\title{
Pornografias: \\ Disputas em torno de Sade
}

\author{
GUILHERME GRANÉ DINIZ \\ UNIVERSIDADE DE SÃO PAULO
}

\section{Resumo}

A relevância da recepção da literatura do Marquês de Sade ainda está por ser plenamente compreendida. Ela se dá não apenas na chave da filosofia, mas também na da arte. Nesse aspecto, encontramos Sade no cinema europeu de vanguarda, no cinema hollywoodiano e no pornográfico. Andrea Dworkin ressaltará uma suposta afinidade entre a escrita sadeana e a moral sexual da encenação pornográfica: a da predação e ódio à mulher. No entanto, essa apropriação é disputada. Angela Carter oporá à visão de Dworkin a "mulher sadeana": Sade teria concebido uma liberdade sexual feminina sem precedentes. Nesse sentido, é notável a influência do imaginário sexual sadeano em filmes pornográficos críticos da pornografia tradicional. Sendo assim, é interessante retraçarmos e considerarmos essas disputas e apropriações de Sade, de modo a termos uma compreensão melhor de sua relevância para a filosofia e arte contemporâneas.

Palavras-chave: Marquês de Sade; pornografia; sex wars.

\section{Abstract}

The relevance of the reception of the Marquis de Sade's literature has yet to be fully understood. It takes place not only in philosophy, but also in art. In this aspect, we find Sade in the vanguard European cinema, in Hollywood cinema and in pornography. Andrea Dworkin highlights a supposed affinity between sadean writing and the sexual morals of pornographic staging: that of predation and hatred for women. However, this appropriation is disputed. Angela Carter will oppose Dworkin's vision with the "sadean woman": Sade would have conceived an unprecedented female sexual freedom. In this sense, it is remarkable the influence of the sadean sexual imaginary in pornographic films that propose themselves as a critique of traditional pornography. Therefore, it is interesting to retrace and consider these disputes and appropriations of Sade, in order to have a better understanding of its relevance to philosophy and contemporary art.

Keywords: Marquis de Sade; pornography; sex wars. 
Uma das primeiras questões que salta aos olhos quando se estuda o pensamento do Marques de Sade é a história de sua recepção. Sade fora um aristocrata, romancista e filósofo francês do séc. XVIII. Nisso, Sade não fora um homem singular em seu tempo. Suas perversões sexuais - bem mais domesticadas em sua vida que em sua literatura - eram lugar comum entre a nobreza da época. (MORAES, 2011, p. 92). O romance filosófico com conteúdo erótico ou mesmo pornográfico era praticado - de forma controversa, mas sem maiores consequências - por vários outros autores. Alguns, como La Bretonne, Diderot e Laclos chegaram até a ficar consideravelmente famosos por obras cujas descrições gráficas e imoralidade dos personagens ainda são chocantes para nossa sensibilidade. Sade também ficara famoso com a publicação de algumas de suas obras, mas a atenção que atraíra para si fora de um tipo bastante diferente: passou quase metade de sua vida preso, tendo sido rotulado por todos os regimes sob os quais viveu (Antigo Regime, Revolução Francesa e Império napoleônico) como subversivo e perigoso. No séc. XIX, por sua vez, é praticamente esquecido; no máximo é relembrado como uma anedota ilustrativa das perversões sexuais que começavam a ser sistematizadas pela psiquiatria da época. É apenas no começo do séc. XX, principalmente devido aos pensadores e artistas surrealistas, que ressurge o interesse em seu pensamento. Mas, nesse momento, essa fortuna sadeana será revertida: se no começo do século os livros de Sade ainda circulavam em edições amadoras ou para clubes de leitura privados; e nos anos 50 o editor Jean-Jacques Pauvert por pouco evitou ser preso por ter publicado as obras completas de Sade; na década de 90 Sade foi publicado na prestigiosa Bibliothèque de la Pléiade, coleção que, "dado seu alto prestígio, tradicionalmente tem a função político-editorial de determinar no mercado e na academia franceses o que é ou não cânone literário" (GRANÉ DINIZ, 2018b, p. 118). Foi o trabalho de todo um século fazer Sade passar de pornógrafo a clássico, e seria ingênuo pensar que essa mudança tem algo a dizer apenas sobre a obra mesma de Sade, e não também sobre a sensibilidade da época. Na compreensão dessa história peculiar da recepção de Sade, é comum tratar da questão por seu aspecto filosófico. No entanto, essa compreensão é limitada se não levarmos em consideração como essa recepção se deu na produção artística do séc. XX. Em nosso caso, o objetivo será tentar entender como Sade foi incorporado não apenas pela "alta cultura" erudita das vanguardas, mas também pelo cinema comercial de Hollywood e pelo cinema pornográfico, tanto em sua corrente ou matriz mais tradicional quanto naquela mais recente. $\mathrm{O}$ que buscaremos neste breve ensaio será mostrar um pouco dessa recepção nos três registros, focando nesse último.

A linguagem literária de Sade, como dizíamos, prestou-se a diversas adaptações cinematográficas, que a mobilizaram em sentidos bastante diferentes. Talvez 
possamos mesmo dizer que essas formas diversas de representar Sade no cinema correspondem, ao menos em partes, ao espectro de recepções teóricas de sua obra. É bastante evidente isso, por exemplo, no Salò ou os 120 Dias de Sodoma (1975), de Pasolini, que abre seus créditos com uma breve bibliografia de textos clássicos sobre Sade. Pasolini transpõe a ação dos 120 Dias de Sodoma ${ }^{13}$ da França pré-revolucionária para a Itália fascista. Assim como a obra de Sade envolve um comentário sócio-político sobre a França absolutista pré-revolucionária, o filme de Pasolini pretende ser um comentário sobre a experiência totalitária italiana. Em seus escritos, Pasolini propõe uma interessante teoria sobre o fascismo, que vai em sentido semelhante ao de outros autores da época que tratam do mesmo tempo. Pasolini considera que, através de seu laço estreito com a mentalidade capitalista, o fascismo torna-se mais que uma forma de governo, restrita a certa experiência histórica: é um modo de vida que se propaga e enraíza na mesma medida que a forma da mercadoria passa a tomar todos os âmbitos da vida ${ }^{14}$. Esse diagnóstico grave da época tem como corolário a ideia de que as possibilidades sócio-culturais de emancipação são cada vez menores: na medida em que cada vez mais aspectos da vida contemporânea são incorporados à lógica cultural do capitalismo, menos seriam os pontos de apoio e resistência contrários às forças políticas reacionárias. Nesse sentido, Salò seria a abertura de uma nova etapa na produção de Pasolini (que restou inacabada, devido à morte violenta do cineasta): em contraposição a sua Trilogia da Vida, que celebra o amor e a sexualidade, inauguraria uma Trilogia da Morte. A primeira dessas duas trilogias consiste nos filmes Decameron (1971), Os Contos de Canterbury (1972) e A Flor das Mil e Uma Noites (1974) Os filmes são baseados em notórias obras eróticas da Idade Média (salvo, é claro, As Mil e uma Noites), e são bastante característicos pelo tom festivo e alegre que retrata as ações sexuais, muitas vezes "desviantes", dos personagens. Notadamente, a figuração da sexualidade nesses filmes enfatiza os aspectos lúbricos e lúdicos do prazer homoerótico, mesmo daquele que eventualmente envolva atos de violência e degradação. A opção por narrativas que são - já em sua matriz literária original - fragmentárias ressalta formalmente a ruptura com a lógica e

13 Comentando de maneira resumida, Os Cento e Vinte Dias de Sodoma é a história de quatro libertinos que enriqueceram às custas do Estado ao fim do Antigo Regime. Eles se casam um com a filha do outro e vão a um castelo escondido nas profundezas da Floresta Negra celebrar suas núpcias. Para tanto, contratam um amplo séquito, incluindo quatro experientes prostitutas, sequestram um grande número de crianças e organizam orgias ao longo de quatro meses, nas quais matam a maior parte desse grupo. O cerne em torno do qual as orgias são realizadas são as histórias contadas pelas prostitutas: na medida em que elas relatam perversões cada vez mais graves e sinistras pelas quais passaram em suas vidas, os libertinos se permitem vilipendiar mais as vítimas.

14 Cf., sobre Salò, NAZÁRIO, 1993. 
a linearidade que informam o cinema mimético. Se a vida e a experiência quotidianas, com sua lógica e sensibilidade lineares, estão maculadas pela experiência do capitalismo liberal e do nazismo, caberia ao cinema formular novas formas de sensibilidade estética e erótica.

Projeto frustrante para Pasolini justamente devido a seu sucesso: o êxito comercial dos filmes da trilogia da vida exporia a captura da linguagem cinematográfica pelo capitalismo, e o caráter imanente da crítica que ele tentaria expor. Nesse sentido, Pasolini efetivamente reconsiderara suas reflexões sobre as possibilidades da sexualidade, especialmente a homoerótica, operar como crítica ao sistema capitalista e às formas de vida instauradas. Enquanto em sua trilogia da vida celebra-se a liberdade das sociedades fechadas de libertinos e amantes, que escapam das amarras morais de sua época na criação, em Salò a própria experiência dos grupos homossexuais herméticos aparece como contaminada pela violência: ao fim do filme, dois jovens que são "elevados" de vítimas a auxiliares dos carrascos valsam ao som de uma canção militar fascista, enquanto seus colegas de cativeiro são torturados, em uma cena que remete à reflexão de Agamben sobre o sentido histórico dos campos de concentração. Uma das memórias de Primo Levi de sua passagem por Monowitz foi uma partida de futebol disputada entre os Sonderkommando e os guardas nazistas. Assistindo à partida, vítimas e carrascos reencenavam uma cena do quotidiano italiano, em que equipes de futebol de bairro disputavam enquanto eram assistidos pelos moradores:

A alguém essa partida poderá talvez aparecer como uma breve pausa de humanidade em meio a um horror infinito. Aos meus olhos, pelo contrário, como àqueles das testemunhas, essa partida, esse momento de normalidade, é o verdadeiro horror do campo. Uma vez que poderíamos, talvez, pensar que os massacres terminaram - mesmo se aqui e ali se repetem, não muito longe de nós. Mas aquela partida nunca terminou, é como se durasse ainda, ininterruptamente (AGAMBEN, 2006, p. 24).

A irrupção anódina da normalidade nos campos de concentração não diminui o horror da experiência nazista; pelo contrário, macula toda normalidade possível no mundo após o holocausto. A experiência quotidiana e nobre do amor - mesmo na forma contestatória do homoerotismo - faz parte da normalidade que tornou possível o nazifascismo; não aponta para fora dele.

No limite, conforme mencionávamos, uma das "teses" do Saló de Pasolini consistiria em mostrar que nem mesmo o próprio cinema pode apontar para um ponto além da experiência fascista de vida: 
A cena da seleção [das vítimas] não é diferente do teste para um filme (é, de fato, uma paródia de um teste), como na Intervista de Pasolini (1987). É como lançar uma rede, para capturar o peixe certo, apropriado, desejado, adequado, belo e comestível. Nos filmes, os atores devem ser perfeitos, especialmente as estrelas, especialmente as estrelas femininas, e especialmente nos filmes de Hollywood. Para Pasolini (e para o Marquês de Sade) o perfeito é uma oportunidade, não para celebração, mas desecração, vilipêndio, os exaltados serem rebaixados e violados. (ROHDIE, 2019).

A trilogia da morte, da qual apenas Salò chegou a ser gravado, propõe-se não mais como oposição a mas como denúncia do estado do cinema à época. É interessante que Pasolini tenha escolhido Sade - um autor historicamente atacado, criticado e vilipendiado - como sendo o representante maior e verdadeira face do capitalismo moderno, e associe seu processo literário ao processo cinematográfico hollywoodiano. Já algumas décadas depois, em Contos Proibidos do Marquês de Sade (2000), de Peter Kaufmann, Kate Winslet, notória star hollywoodiana, co-estrela um filme livremente baseado nos últimos anos de vida de Sade. A própria caracterização do personagem do Marquês já revela a postura que o cineasta e sua produção tomam face a Sade: ele é retratado como um senhor nobre, altivo, cabelos brancos bem arrumados, ligeiramente excêntrico, perigosamente sedutor (e interpretado por Geoffrey Rush). Visão sem muito amparo na realidade: "eu não percebi, a princípio, nele, senão uma obesidade enorme, que prejudicava seus movimentos o suficiente para lhe impedir de empregar um resto de graça e de elegância" (LELY, 1973, p. 543). É evidente o tom de exaltação que o filme de Kaufman compartilha com boa parte da literatura sobre o Marquês do séc. XX, que mostra de Sade como uma espécie de anti-herói do Iluminismo, comprometido de forma inabalável com a liberdade absoluta de expressão para o desvelamento de verdades que lhe "foram reveladas" no cárcere (BATAILLE, 2013, p. 95). Nas palavras do crítico Roger Ebert (2000):

Os Contos Proibidos do Marquês de Sade de Philip Kaufman nos proveem um Marques edulcorado para consumo popular (você não descobrirá aqui que ele pensava que um aristocrata como ele tinha o direito de cometer assassinato na busca pelo prazer). Esse Marquês não representa tanto a licença sexual quanto a liberdade da expressão artística.

De fato, o retrato de Sade é feito através de uma montagem bem selecionada de sua personalidade e vida, de um modo tal que nos leva não apenas a simpatizar com seu desejo indômito, mas participarmos da sedução de sua figura cativante 
e atraente. Somos postos, nesse sentido, no seio da dinâmica sensual do filme: o senhor aristocrata seduz a jovem Madeleine, introduzindo a ingênua burguesa à liberdade sexual e moral, e formando com ela o par romântico central da trama. Logo Sade, que, em seus escritos, nunca hesitou em criticar severamente o amor romântico. E, de fato, é muito apropriado que se associe a crítica de Pasolini ao cinema hollywoodiano e suas stars. Como mencionávamos, Pasolini compreende que a nazificação da vida comum passa pelo processo de enraizamento e expansão do capitalismo. Nesse sentido, não só a sexualidade é reduzida a uma sexualidade burguesa, mas o potencial crítico da linguagem cinematográfica também se torna inócuo devido à inserção do filme em circuitos comerciais. Sem falar dos méritos estéticos do filme, Pasolini parece estar certo ao dizer que, no nível da narrativa, o cinema comum, comercial, despotencializa a crítica que a linguagem cinematográfica poderia oferecer aos modos de vida correntes. No caso, fagocita e torna inócuo um de seus principais críticos.

Notadamente, essa disputa sobre as possibilidades e limites à emancipação através da linguagem cinematográfica está ligada ao papel da representação do sexo. Como bem mostra Mariana Baltar (2011, p. 473), na esteira do trabalho pioneiro de Linda Williams (2008), em sua estruturação, funcionamento e mesmo origem o cinema pornográfico é especialmente ligado ao documental. Com outros gêneros cinematográficos mais populares, como o drama, a comédia romântica ou o filme de terror, a pornografia tem em comum a tentativa de elicitar uma reação não meramente emocional ou intelectual, mas física: assim como a comédia gera o riso ou o drama o choro, a pornografia faz o corpo reagir na forma da excitação. No entanto, diferentemente desses outros gêneros e à semelhança do documentário, existe um elemento intelectual, quase científico, no cinema pornô: trata-se de tornar visível o que é oculto. O cinema pornográfico seria uma forma de conhecer o sexo, de se fazer presente no momento reservado da intimidade de um casal. Não por menos - elas concluem junto a Foucault - a pornografia é contemporânea a Freud. Ambas as autoras fazem esse apontamento em chave crítica (no mesmo sentido da crítica de Pasolini): ao criar uma "evidência visível" de certa forma de funcionamento e relação entre corpos - evidência do ato heterossexual - naturaliza a atuação em cena, mostrando-a como se fosse a forma típica, privilegiada, ou mesmo viável e realista de relação sexual (o que, sabidamente, não é o caso). Isso não preclui, no entanto, a via de uma pornografia crítica; que ressalte sua própria artificialidade, explicitando através da retórica cinematográfica os mecanismos por meio dos quais cria a situação de corporalidade retratada. Agamben já lembra bem de como existe, nesse sentido, uma pornografia prescrita e uma proscrita: aquela que reforça as formas típicas de uma sexualidade "sociável" e de uma contrária à moral social corrente. O Saló de Pasolini foi proibido 
em diversos países, não por menos, sob a acusação de ser um filme pornográfico: de fato, trata-se de uma crítica pungente e generalizada da sexualidade sob o capitalismo.

Nem entraremos de fato na discussão complexa sobre o que é ou não pornografia, mas Salò não é o tipo de filme que, hoje, tenderíamos a chamar de pornográfico. Em se tratando do cinema pornô como o entendemos de forma geral, a passagem dos anos 60 para os 70 foi crucial. Em 72, o filme Garganta Profunda, de Gerard Damiano, causou um impacto significativo no modo como o retrato cinematográfico do sexo era feito, ao inserir as cenas de sexo explícito em meio a uma narrativa de comédia. O cinema pornográfico enquanto tal "gravita em torno da noção - e dos modos de sustentar tal noção - de que ao dar a ver a verdade, corpórea, do sujeito, dá-se a ver o sujeito naquilo que lhe é mais próprio: seu sexo" (BALTAR, 2011 p. 479); Garganta Profunda (1972) intensifica esse movimento ao fazer da descoberta sensível do sexo seu próprio tema: trata-se da história de uma mulher incapaz de prazer sexual, que busca ajuda médica (de um psiquiatra!) acerca do tema e descobre ter o clitóris localizado no fundo da garganta. A partir daí, em uma explícita analogia com contos de fadas, Linda se dedica a fazer sexo oral em uma série de homens até encontrar aquele cujo órgão "encaixe" adequadamente em si e casar-se com ele: sua carreira na "devassidão" é prelúdio para o "felizes para sempre" da vida marital e sua sexualidade sancionada. $\mathrm{O}$ alto valor de produção do filme e a conexão entre pornografia e o cinema mais comercial levou ao cinema adulto um público que, até então (e desde então), se recusara sistematicamente a participar desse tipo de exibição. (BLUMENTHAL, 1973). A ideia de que filmes pornô tivessem um roteiro, uma ambientação, trilha sonora, atuações, etc., inaugurou o que ficou conhecido como a "era de ouro" do cinema pornô, e naturalmente levou à busca por histórias que pudessem ser adaptadas nos novos padrões desse gênero.

Um dos mais importantes cineastas desse momento, o espanhol Jesús (também conhecido como Jess) Franco teve na obra de Sade uma fonte constante de inspiração. Damiano conseguira a abertura de seu Garganta Profunda ao público em geral através da associação entre pornografia e comédia; Franco ligou pornografia e cinema de terror. Além de uma série de histórias originais de fantasia e ficção científica, Franco recorreu à literatura de Sade como fonte para seu cinema. Seus dois primeiros filmes sobre Sade foram baseados, respectivamente, em Justine e A Filosofia na Alcova. A história de Justine é conhecida: trata-se de uma jovem moça que a morte dos pais deixa desamparada. Sua irmã, Juliette, prontamente aceita que o único destino possível para uma jovem de sua idade é a prostituição. Mas, Justine, sendo uma moça muito religiosa, se recusa a seguir a irmã, preferindo tentar encontrar um trabalho que não ofenda suas sensibilidades 
morais. Passará, então, toda sua história (são mais de mil páginas!) sendo sequestrada, estuprada, aviltada, etc., até sua morte pelas próprias mãos da providência divina que ela não cansara de louvar. A Filosofia na Alcova, por sua vez, conta uma história quase que diametralmente oposta: a jovem Eugénie é convidada por sua amiga, Mme. de Sainte-Ange, para uma visita, na qual Sainte-Ange prepara a iniciação da jovem na libertinagem. Diferente da história de Justine, não se trata de violentar o corpo da jovem, e sim de corromper sua alma. Com a ajuda de seu irmão e do experiente libertino Dolmancé, Sainte-Ange ensina a Eugénie não apenas algo sobre o prazer, mas também os aspectos morais da libertinagem, ajudando-a, assim, a se livrar das amarras cristãs nas quais fora educada. Das diversas adaptações que Franco faz de Sade, destacam-se duas características no trato com essa fonte. Primeiramente, a "infidelidade"; "adaptar Sade literalmente é praticamente impossível em uma tela de cinema, nem mesmo de cinema pornográfico, pois tanto sua estrutura episódica e repetitiva quando sua maneira de dialogar resultam demasiado líricas, teatrais, no melhor dos casos, mas muito pouco cinematográficas" (BLANCO, 2019, p. 126). Em segundo lugar, uma preferência sobre o ponto nos quais realizar esses cortes: mantém-se sem maiores ajustes as cenas sexuais; são cortados esses elementos "líricos", o discurso libertino sobre o sexo. A diferença entre as histórias de Justine e de Eugénie é a diferença entre captividade e libertação. Mas isso apenas porque Justine, à diferença de Eugénie, é impermeável aos discursos dos libertinos. Eugénie, através da evidência sensível do prazer, se convence que a imoralidade é muito desejável, de modo que cede e acede à posição dos libertinos; Justine, recusando seus raciocínios, permanece como sua vítima. Ao remover o elemento discursivo-filosófico da literatura sadeana, Jésus Franco retrata essas histórias polarmente diferentes de uma maneira semelhante: enfatiza os sequestros, as torturas, os estupros. Para ressaltar a violência, Franco muda, a ponto de inverter o sentido, a história da Filosofia na Alcova.

Ora, a depender de Andrea Dworkin, não é por acaso que isso se dá. $\mathrm{Na}$ passagem entre os anos 80 e 90, nos Estados Unidos, travava-se uma disputa muito importante para a história do pensamento feminista: as sex wars. Como o nome bem indica, essa disputa teve por objeto a percepção de diferentes grupos feministas sobre o sentido das práticas e teorias sexuais nas sociedades ocidentais; especialmente no que diz respeito à experiência sexual da mulher. Dentre os desdobramentos desse debate, foi central a disputa sobre a pornografia. Autoras muito relevantes no momento, Andrea Dworkin e Catharine McKinnon conseguiram aprovar diversas leis municipais que proibiam a circulação de filmes pornográficos, considerando-os como violações aos direitos das mulheres. Catalisador para essa disputa fora o relato da atriz Linda "Lovelace" Boreman, a estrela de Garganta Profunda. Em um relatório sobre a indústria pornográfica, parte de 
um recenseamento promovido por Ronald Reagan sobre o tema, Boreman testemunha que "virtualmente toda vez que alguém assiste a esse filme, eles estão me assistindo ser estuprada”. (ESTADOS UNIDOS, 1986, p. 829). Isso confirmou aos olhos dos conservadores a relação entre pornografia e criminalidade, e, aos olhos das feministas, a relação entre pornografia e violência contra a mulher. Em seu clássico Pornografia, Dworkin propõe uma análise e genealogia da moral sexual vigente. Partindo do relatório comissionado por Reagan, Dworkin mostra que, empiricamente, a pornografia cinematográfica é constantemente acompanhada de outros crimes de cunho sexual. (DWORKIN, 1989, p. XV). Mas a ligação entre pornografia e estupro seria mais profunda que apenas uma correlação costumeira entre ambos. Na medida em que "pornografia é a teoria, e o estupro, a prática", (ROBIN, 1980, p. 139), o Marquês de Sade, enquanto analista do desejo (MARQUÊS DE SADE, 1990, p. 69), teria sido o pornógrafo típico. Partindo de uma interpretação de dados da vida de Sade, Dworkin busca mostrar como seus discursos de justificação da libertinagem não são apenas reflexões teóricas abstratas, mas visariam à defesa dos muitos atos perversos pelos quais fora condenado (como envenenamento, estupro e maus-tratos a prostitutas, sexo com moças menores de idade, sodomia, etc.): literalmente, Sade postularia a teoria que informava e justificava - moral e juridicamente - sua prática (DWORKIN, 1989, p.70). Já mencionamos que uma das características mais marcantes da erótica sadeana consiste mesmo nessa ênfase quase obsessiva sobre a argumentação. É possível encontrar em diversas passagens da obra de Sade discursos no fato de que para seus personagens nos quais se busca provar nunca basta o mero exercício de um ato sexual; é sempre necessário justifica-lo filosoficamente. Especialmente, é preciso constantemente fazer a prova de que o prazer sexual só pode ser atingido pela dor alheia:

É da visão daquele que não goza do que eu tenho e que sofre que nasce o charme de dizer: "eu sou, então, mais feliz que ele" [...] e eis o que explica as infâmias que me foram reprovadas toda minha vida. As pessoas que não me conheciam me chamavam de duro, feroz e bárbaro, mas, zombando de todas essas denominações, eu seguia meu caminho; eu fazia, convenho, o que os tolos chamam de atrocidades, mas eu estabelecia prazeres de comparação deliciosos, e eu era feliz (MARQUES DE SADE, 1990, p. 157).

Uma vez que "não é no gozo que consiste a felicidade, é no desejo, é em quebrar os freios que se opõem ao desejo" (MARQUÊS DE SADE, 1990, p. 156), o estupro é o corolário natural e verdadeiro ápice do ato sexual; o prazer se encontra quando, em vez de alegremente ceder e se engajar no ato (como na Trilogia da 
Vida de Pasolini), o parceiro "opõe freios" à volúpia ${ }^{15}$.

De fato, isso parece mesmo verdadeiro se observamos aquelas adaptações pornográficas de Sade. Como comentávamos, Jesús Franco não apenas considerara mais adequado formular uma versão cinematográfica da história das repetidas violações de Justine em vez do contraponto libertador de sua irmã, mas adaptara a história da Filosofia na Alcova de maneira a transformar um romance sobre a iniciação sexual de uma moça e a descoberta do próprio corpo e seus prazeres em outra história de violação e estupro. Mais significativo ainda, Franco não deixa de ser coerente com a lógica interna do pensamento sadeano: $o$ ato sexual, em si, é inescapavelmente violento, sangrento e destrutivo. A diferença entre o engajamento ativo e prazeroso ou a subjugação violenta não está nas ações em si - o libertino nunca se recusa a ser espancado, punido ou, eventualmente, até mesmo morto - mas no discurso que lhes atribui sentido. Ao menos no que diz respeito àqueles primeiros anos da pornografia moderna, Dworkin estava certa. Mais delicado seria notar que, a despeito da carga erótica de Contos Proibidos do Marquês de Sade ser bastante mitigada em relação ao Salò ou aos filmes de Franco, essa obra também se enquadraria bem no escopo da crítica à "sadofilia" feita por Dworkin. A "liberdade sexual" da qual Sade seria o representante, e à qual ele introduziria Madeleine, Dworkin (1989, p. 209) a entende como a mais recente, eficiente e sutil ferramenta de dominação sexual masculina: direita, esquerda, liberais e conservadores colocariam suas diferenças de lado na defesa dos "direitos" dos homens; da pornografia como modo de vida e ordenação social. No filme, a "libertação" de Madeleine da moral sexual burguesa culmina na despossessão de seu corpo, o qual será - como o de Justine - violentado e destruído em nome da libertinagem sadeana. Uma vez atrelado ao regime de visibilidade instituído pelo cinema pornográfico, todo ato sexual feminino - mesmo aquele apenas entre mulheres - seria colocado à disposição de um olhar masculino onipresente, capaz de reintegrá-lo aos circuitos da sexualidade heteronormativa como uma forma de "atiçar" o desejo masculino. É o mesmo diagnóstico de Pasolini: nenhuma sexualidade, nem mesmo aquela contrária à moral social das sociedades capitalistas, pode agora ser pensada como caminho para uma efetiva libertação. Saló, Garganta Profunda, A Filosofia na Alcova, Contos Proibidos do Marquês de Sade: a despeito das significativas diferenças nas histórias, nos atos sexuais retratados, nos uso das técnicas cinematográficas, são unidas por uma temática comum: a dominação, sexual e violenta, do corpo de jovens moças por homens mais velhos, culminando na "retirada de circulação" desse corpo da economia sexual; ou pelo

15 A diferença é que Pasolini reconhece isso como a verdade do ato sexual sob a égide do capitalismo, não do ato sexual em si. 
casamento ou pela morte. Mas, para Dworkin, a questão de uma moral sexual focada na dominação da mulher já estava posta desde bastante antes do surgimento e consolidação do cinema pornográfico. Na verdade, deriva - não por coincidência - da obra de Sade.

De fato, em um primeiro momento, a associação proposta por Dworkin parece se sustentar, ao menos como regra: o objeto principal da fantasia pornográfica é o estupro, e Sade foi muito possivelmente o autor que primeiro e com mais insistência tematizou a relação necessária entre prazer sexual e violência. Jésus Franco, então, viria como que corrigir Sade onde ele claudicou - se desviou pelas sendas da virtude - extraindo o corolário estupratório de seu pensamento. Mas, como mencionamos brevemente, Dworkin foi uma autora central em um debate. Sua posição, longe de ser hegemônica, foi contestada dentro do próprio feminismo americano. Angela Carter, outro nome maior da época, celebra Sade em seu A Mulher Sadeana como o precursor de uma liberdade sexual feminina inaudita. Especificamente, a literatura de Sade apontaria diretamente para o limite do pensamento anti-pornográfico:

Pornógrafos são os inimigos da mulheres apenas porque nossa ideologia contemporânea da pornografia não abrange a possibilidade da mudança, como se nós fossemos escravos da história, e não seus autores, como se relações sexuais não fossem a expressão de relações sociais, como se o sexo ele mesmo fosse um fato externo, imutável como o clima, criando a prática humana, mas nunca parte dela. (CARTER, 2003, p. 4).

A teoria de Sade, mais que da necessária submissão de um sexo pelo outro, trataria do aspecto eminentemente social da atividade sexual, e da possibilidade de conscientemente reformularmos as práticas e a moral sexual ${ }^{16}$. De fato, não se pode negar que, se este não for $o$ tema central de Sade, é um de grande destaque. Em seu A Filosofia na Alcova, Sade associa a mudança global na forma da vida social com uma visão nova sobre o sexo. A Revolução Francesa, para toda a geração de Sade, significara uma possibilidade de ruptura com a ordem do passado, e de uma consequente refundação da sociedade, agora de maneira consciente e reflexiva. Um desses pontos de ruptura foi com o cristianismo. A separação entre Igreja e Estado teria sido o passo inicial na possibilidade de uma sociedade livre das crenças morais e pudores cristãos, que restringiam o desejo e mantinham as pessoas em constante submissão. Mais ainda, uma revolução, sendo uma ruptura com a ordem estabelecida, necessita de agentes revolucionários dotados de uma

16 Ideia com a qual Simone de Beauvoir concorda. 
energia imoral. O estímulo da imoralidade será uma tarefa para o governo revolucionário, que deve, para isso, garantir a existência de prostíbulos públicos. Mas, sendo uma sociedade pautada na igualdade dos cidadãos, o prostíbulo não seria apenas o lugar onde homens poderiam dominar sexualmente tantas mulheres quanto quisessem:

Se a instituição das casas de deboche público tem por finalidade dar vazão aos desejos, cujo represamento significa um problema do ponto de vista do funcionamento da república, as mulheres têm tanto mais o direito de frequentá-los - em busca dos objetos de luxúria que bem desejarem (lembrando que nessas casas não só estarão disponíveis mulheres, mas homens, crianças e outros seres), para realizar os atos que lhes aprouverem - uma vez que seus desejos são mais intensos. (GRANÉ DINIZ, 2018a, p. 190).

A intensidade e imoralidade do desejo é precisamente do que decorre a importância da sexualidade feminina na sociedade revolucionária. A Revolução Francesa apenas teria sucesso se conseguisse dar esse último passo: refundar a vida pública em torno da sexualidade feminina. Personagens como Sainte-Ange, Juliette, Augustine ou a Srta. de Téroze ativamente lutam por sua liberdade e independência, tematizando explicitamente as injustiças a que são submetidas enquanto mulheres. O fato é que dizer da literatura de Sade que prefere o retrato da violência contra mulher é equivocado. Juliette e sua amiga Clairwil não apenas se dedicam a torturar e assassinar tanto homens quanto mulheres, mas Clairwil declara preferir "vingar seu sexo" (MARQUÊS DE SADE, 1998, p. 578) quando da escolha de suas vítimas:

\begin{abstract}
Mas suas grandes mulheres, Juliette; Clairwil; a princesa Borghèse; Catarina, a Grande, da Russia; Charlotte de Nápoles, são ainda mais cruéis dado que, uma vez que experimentaram o poder, uma vez que elas sabem usar sua sexualidade como instrumento de agressão, elas o usam para se vingar das humilhações que elas foram obrigadas a aguentar enquanto objetos passivos da energia sexual dos outros (CARTER, 2003, p. 27).
\end{abstract}

Segundo Carter, o que Sade teria compreendido é a indesejabilidade do acréscimo "moral" - aqui entendido à maneira francesa; o que é espiritual, simbólico, intelectual, oposto ao físico - ao ato sexual. No sexo não se trata de "homem", "mulher", "masculino", "feminino" - principalmente de "atividade" e "passividade". Trata-se de indivíduos - com todas as determinações sociais de praxe, mas, ainda assim - singulares em sua experiência do corpo: ser mulher não significa 
ser passiva, ser homem não significa ser ativo; tanto em relação ao próprio desejo quanto socialmente. As reiteradas profanações sadeanas - contra a beleza, a virtude, a pureza, a castidade, etc. - são etapas na dissolução da imagem idealizada, do signo "mulher", que permitiriam liberar a pessoa de carne e osso que lhe subjaz.

Enfim, mais importante ainda é considerar que as perversões literárias de Sade não são escritas como apologia, mas como fantasia: não se trata de justificar a ação, mas de imaginá-la. Ora, não é difícil de percebermos como uma parte significativa - senão a maior parte - das perversões descritas por Sade sequer poderiam ser postas em prática. Quando não exigem do corpo operações em volumes e quantidades impossíveis -

[...] eu os coloquei dois em minha boceta, um em meu cu, eu chupei um, dois se colocaram sob minhas axilas, um em meus cabelos, eu masturbava um em cada mão, o décimo se masturbava sob meus olhos: mas eu proibi o orgasmo; eles deviam todos variar dez vezes (MARQUÊS DE SADE, 1998, p. 778),

- contrariam de forma explícita e direta as próprias leis da natureza:

ele fode uma cabra de quatro, enquanto o açoitam. Ele faz um filho nessa cabra, que ele enraba por sua vez, apesar de ser um monstro (MARQUÊS DE SADE, 1990, p. 331).

Quando se considera a questão por esse ângulo, torna-se logicamente impossível um cinema pornográfico que pretenda pôr em imagens as perversões sonhadas por Sade. Antes, como Barthes argumentará, parece que o domínio próprio da erótica sadeana é, justamente, onde a imagem não alcança. (BARTHES, 1982, p. 79). Se, então, for o caso de associar a literatura sadeana a algum tipo de pornografia, essa não há de ser aquela que - como a de Franco ou de Damiano - busca diretamente representar o corpo. É o caso de se buscar alguma afinidade com o pensamento sadeano na pornográfica mais recente, que, levando em conta as questões postas nas sex wars, pretenda pensar formas de retratar o sexo que contestem a moral sexual vigente. em um regime realista ou naturalista de plena visibilidade (como na pornografia tradicional).

Novamente, para nos limitarmos a um exemplo, queremos mencionar brevemente o trabalho da diretora pornô Vex Ashley, cujo impacto na indústria pornográfica tem crescido de maneira relevante. Em um de seus primeiros curta-metragens - Imaculado Coração - vemos uma atriz paramentada como Virgem Maria entrando e saindo de foco em uma cena de masturbação solitária. Há uma ampla referência a um imaginário cristão, não apenas na paramentação da atriz, 
mas também no uso de símbolos e cenários religiosos, além, é certo do próprio título. Sem a preocupação de uma narrativa cinematográfica convencional de Garganta Profunda ou dos Contos Proibidos do Marquês de Sade, apenas no uso desses recursos imagéticos se conta uma "história" cuja "imoralidade" é flagrante. A masturbação é ato sexual "imaculado" ao dispensar a perda da virgindade ou o contato sexual extramarital. Trata-se de reimaginar a história bíblica, evidenciando na narrativa de pureza e castidade de Maria um potencial erógeno transgressor: a exploração por uma mulher de seu próprio corpo, sexualidade e prazer. Todos os símbolos religiosos ligados à mariolatria recebem, assim, um novo uso: as velas acesas em devoção viram sex toys; as auréolas dos santos servem para iluminar a cena. Nessa "releitura" anticristã de Maria, é a feminilidade como um todo - inclusa a interdição sexual do corpo feminino - que é reconsiderada, a própria proibição religiosa sendo posta como elemento de prazer.

A ideia de que é pela crítica do cristianismo que se atingirá a possibilidade de uma nova sexualidade é um dos pilares da literatura sadeana. Um dos poucos pontos de unanimidade entre os libertinos é sua aversão pela religião cristã. Mas é singular o procedimento crítico dos libertinos:

Entre os carmelitas tem um religioso de trinta e cinco anos, belo como o dia, que eu cobiço há seis meses; eu quero absolutamente ser fodida por ele, mas por um meio bem agradável: nós vamos nos confessar a ele; nós esquentaremos sua cabeça pelos detalhes mais lúbricos; ele ficará duro; eu estou persuadida de que, por iniciativa própria, ele nos fará propostas; ele nos indicará o modo de vê-lo, nós o renderemos ali mesmo e nós o esgotaremos... Nós não ficaremos nisso; nós comungaremos, nós recolheremos as hóstias em nossos lenços, depois nós voltaremos almoçar em sua casa e fazer horrores sobre esse miserável símbolo da infame religião cristã. (MARQUÊS DE SADE, 1998, p. 582).

Qual o sentido de profanar hóstias para quem não crê que elas tenham qualquer sentido ou poder? A questão posta no trecho, na verdade, consiste em um problema comum aos libertinos sadeanos, e que não se limita à religião: libertinos experimentam com frequência desejos cuja saciedade seus frágeis corpos não suportam: fustigações, maratonas sexuais, banquetes de centenas de pratos e dezenas de garrafas de vinho. O corpo não totaliza o prazer libertino; uma parte fundamental de sua sexualidade se encontra precisamente nesse âmbito simbólico-imaginário que começa onde o corpo termina. Isso exige, é claro, uma nova sensibilidade, nova estética: a forma que o libertino tem de aceder àquele prazer que ultrapassa os limites do corpo é um procedimento masturbatório que 
culmina em "transcrev[er] sobre seus cadernos a espécie de perversão que acabou de lhe inflamar, sem esquecer nenhuma das circunstâncias que puderem ter agravado os detalhes" (MARQUÊS DE SADE, 1998, p. 752). A literatura não era apenas o meio disponível a Sade para registrar suas fantasias eróticas; é mesmo a única forma possível para a realização plena de um desejo que escapa aos limites estreitos da sensibilidade humana. Daí que Barthes critique o Saló de Pasolini: a representação fílmica da obra de Sade falseará sua fonte se se limitar à imagem do corpo e à representação mais ou menos "fiel" do ato sexual.

Essa, talvez, seja a verdadeira herança ou ensinamento sadeano para a pornografia. Outro elemento relevante do Imaculado Coração, de Ashley, é o modo como a câmera não se foca exclusivamente na "ação" em curso, mas atravessa e percorre o corpo da atriz, evidenciando o conteúdo sexual da cena não apenas na representação direta da fricção genital, mas em suas manifestações singulares em cada trecho do corpo. Isso ao ponto do movimento da câmera levar a imagem a sair de foco diversas vezes, como se a carga erótica atingisse a própria forma da visibilidade (SARMET, 2018, p. 557). Como bem aponta Érica Sarmet, em reflexão próxima à de Mariana Balthar, o elemento crítico presente em algumas instâncias da pornografia consiste na desnaturalização do imaginário sexual (o que Angela Carter atribui a Sade): rompe-se com a estética naturalizante da representação "documental" da experiência íntima, evidenciando o artifício da captura da imagem, da edição das cenas, da atuação. Representar a sexualidade sem o enfoque obsessivo nos genitais - o money shot da gramática pornográfica tradicional - é um procedimento que não apenas reproduz algumas das profanações sadeanas, mas responde a sua concepção de erotismo: o prazer culmina "fora do corpo" e fora da imagem do corpo, quando capturado em seus elementos simbólicos e em seu potencial de deformar a própria visibilidade da representação do ato. No mais, vimos como Sade associa a crítica ao cristianismo tanto à emergência de uma nova sexualidade quanto à de uma sociedade centrada no prazer do corpo feminino. Essa associação entre política, prazer, estética, que a crítica do cristianismo opera, está no cerne da pornografia de Vex Ashley.

Enfim, talvez mais que dizer da literatura e filosofia do Marques de Sade que é parte constitutiva das formas como pensamos a sexualidade, tendo nos deixado um legado de dominação semelhante à experiência nazista, ou que é uma pedra de toque para contestá-las, a verdade seja que ela pode ser usada tanto de uma maneira quanto de outra. A recuperação mais ou menos recente do pensamento de Sade parece ter permitido olhar para ele como uma espécie de repositório de nossas próprias projeções: seja como um herói e mártir de uma sexualidade reprimida, seja como inventor sádico de nossa moral sexual atual. Que ambas as posturas sobre a obra de Sade coexistam, sem que nenhuma predomine, é um in- 
dício significativo disso. Eliane Robert Moraes e Sandra Lapeiz (1985, p. 8) consideram que a comum oposição entre pornografia e erotismo é índice da valoração moral feita sobre uma determinada obra. O próprio Saló passa de pornográfico a erótico com a inclusão do cinema de vanguarda em certo cânone estético. O que Pasolini já percebera, e sobre o que Vex Ashley e outras pornógrafas feministas contemporâneas capitalizam, é que essa "imoralidade" da pornografia pode ser deliberadamente assumida como contestação da moral vigente. A associação entre Sade e o cinema pornográfico - seja na crítica, seja no louvor - se relaciona ao fato de que a própria ideia de pornografia possui essa mesma abertura interpretativa que a obra de Sade: em si, contém a possibilidade de ser moralmente aviltante ou sexualmente libertadora. Se for assim, pode ser importante ressaltar em Sade e no cinema pornográfico os potenciais de liberdade contêm: sua crítica dos costumes e do cristianismo, sua defesa radical dos ideais republicanos, suas propostas de transformação utópica da sociedade. Principalmente - algo que essa nova pornografia herda - a ideia de que uma nova sexualidade passa não apenas por uma mudança na estruturação das relações sociais desiguais, mas também por uma nova percepção sobre o corpo e, no limite, uma nova sensibilidade: modos de colocar em relação erótico e estético, tendo o prazer como projeto político (ASHLEY, 2016, p. 190).

\section{Referências:}

A FLOR das Mil e Uma Noites. Direção de Pier Paolo Pasolini. Itália. 1974.

AGAMBEN, Giorgio. Quel Che Resta di Auschwitz: L'Archivio e il Testimone. Torino: Bollati Boringheri. 2016.

ASHLEY, Vex. Porn - Artifice - Performance - and the problem of authenticity. In Porn Studies, vol. 3, nº. 2, 2016.

BALTAR, Mariana. Evidência Invisível - BlowJob, vanguarda, documentário e pornografia. In FAMECOS - Mídia, Cultura e Tecnologia, vol. 18, nº 2, 2011.

BARTHES, Roland. Sade-Pasolini. In Revue d’Esthétique Paris, nº 3, 1982

BATAILLE, Georges. La Littérature et le Mal. Paris: Gallimard. 2013.

BLANCO, Alejandro Mendíbil. Jess Franco: de los márgenes al cine de autor. Análisis del relato cinematográfico. 2019. Tese (Doutorado) - Faculdad de Ciencias de la Información, Universidad Complutense de Madrid, Madrid. 
BLUMENTHAL, Ralph. "Hard-core" grows fashionable - and very profitable. In New York Times, 21 de janeiro de 1973.

CARTER, Angela. The Sadeian Woman: An Exercise in Cultural History. Nova York: Penguin. 2003.

CONTOS Proibidos do Marquês de Sade. Dirigido por Philip Kaufman. Estado Unidos. 2000.

DECAMERÃO. Direção de Pier Paolo Pasolini. Itália. 1971.

DWORKIN, Andrea. Pornography: Men Possessing Women. Nova York: Penguin. 1989.

EBERT, Roger. Quills. In https://www.rogerebert.com/reviews/quills-2000.

ESTADOS UNIDOS. Attorney General's Commission on Pornography: final report. Washington, D.C.: U.S. Dept. of Justice. 1986.

GARGANTA Profunda. Direção de Gerard Damiano. Estados Unidos. 1972.

GRANÉ DINIZ, Guilherme. Essas Doces Ações que vós Chamais de Crimes: Crítica à Modernidade e Crítica do Direito em Sade. 2018. Dissertação (Mestrado em Filosofia e Teoria Geral do Direito) - Faculdade de Direito, Universidade de São Paulo, São Paulo.

. Sade: a Censura no Século XVIII; a Censura Hoje. In Paralaxe, vol. 5, número especial. 2018.

IMACULADO Coração. Direção de

LELY, Gilbert. Vie du Marquis de Sade in MARQUÊS DE SADE, Donathien-Alphonse-François, Oeuvres Complètes, vol. II. Madri: Tête-de-Feuille. 1973

MARQUÊS DE SADE, Donathien-Alphonse-François. Oeuvres, vol. I. Paris: Gallimard. 1990.

Oeuvres, vol. III. Paris: Gallimard. 1998.

MORAES, Eliane Robert. Lições de Sade. São Paulo: Iluminuras. 2011. ; LAPEIZ, Sandra. O Que é Pornografia. São Paulo: Brasiliense. 1985.

MORGAN, Robin. Theory and Practice: Pornography and Rape. In LEDERER, Laura (ed.) Taking back the Night: Women on Pornography. Nova York: William Morrow and Co. 1980 
NAZÁRIO, Luiz. Pasolini. São Paulo: Brasiliense. 1993.

OS CONTOS de Canterbury. Direção de Pier Paolo Pasolini. Itália. 1972.

ROHDIE, Sam. I racconti di Canterbury (Pier Paolo Pasolini)/The Canterbury Tales (Geoffrey Chaucer). In http://www.screeningthepast.com/2012/08/i-racconti-dicanterbury-pier-paolo-pasolinithe-canterbury-tales-geoffrey-chaucer/

SALÓ ou os 120 Dias de Sodoma. Direção de Pier Paolo Pasolini. Itália. 1975.

SARMET, Érica. Pornografia da Vulnerabilidade: estratégias feministas da subversão da normatividade pornográfica. In Imagofagia, vol. 18, 2018.

WILLIAMS, Linda. Screening Sex. Durham: Duke University Press. 2008. 